\title{
OPEN Adequacy of antibiotic prophylaxis and incidence of surgical site infections in neck surgery
}

\author{
M. Alonso-García1,2, A. Toledano-Muñoz ${ }^{2,3}$, J. M. Aparicio-Fernández ${ }^{3}$, \\ F. M. De-la-Rosa-Astacio ${ }^{3}$, D. Rodríguez-Villar², A. Gil-de-Miguel ${ }^{2}$, M. Durán-Poveda² \& \\ G. Rodríguez-Caravaca ${ }^{1,2}$
}

Health care-related infections are frequent and among them surgical site infection (SSI) are the most frequent in hospitals. The objective was to evaluate the adequacy of antibiotic prophylaxis in patients undergoing neck surgery and its relationship with the incidence of surgical site infection (SSI). Prospective cohort study. The adequacy of antibiotic prophylaxis in patients undergoing neck surgery was evaluated. Antibiotic prophylaxis was considered adequate when it conformed to all items of the protocol (antibiotic used, time of administration, administration route, dose and duration). The cumulative incidence of SSI was calculated, and the relationship between SSI and antibiotic prophylaxis adequacy was determined using adjusted relative risk (RR). Antibiotic prophylaxis was administered in 63 patients and was adequate in $85.7 \%(95 \% \mathrm{Cl} 75.0-92.3)$ of them. The cumulative incidence of SSI was $6.4 \%(95 \% \mathrm{Cl} 3.4-11.8)$. There was no significant relationship between antibiotic prophylaxis inadequacy and the incidence of $S S I(R R=2.4,95 \% \mathrm{Cl} 0.6-10.6)$. Adequacy of antibiotic prophylaxis was high and it did not affect the incidence of SSIs.

Surgical site infection (SSI) is the most common healthcare-associated infection (HAI) ${ }^{1,2}$. The incidence of SSI depends on variables that are both intrinsic (sex, age, comorbidities, etc.) and extrinsic (duration and type of surgery, surgeon experience, preoperative preparation of the patient, etc.) to the patient ${ }^{3,4}$ and ranges from 1 and $20 \%$ depending on the type of surgical procedure ${ }^{5}$.

Neck surgery is one of the most important types of otorhinolaryngological surgery. Specific studies that estimate the incidence of SSI in neck surgery report incidences of less than $1 \%$ when the surgery is clean ${ }^{6,7}$ and between 25 and $85 \%$ when the surgery is clean-contaminated ${ }^{8,9}$. These types of infections are of great health importance because they increase the average length of hospital stay, morbidity and mortality, and the healthcare cost per patient ${ }^{10,11}$.

One of the most effective measures for reducing SSI is antibiotic prophylaxis, which is indicated in cleancontaminated and contaminated surgeries and in clean surgeries in which an implant is placed, the operative time is prolonged, the patient is immunosuppressed or that are performed on a specific site ${ }^{12,13}$. The purpose of preoperative prophylaxis is for the antibiotic to reach an optimal concentration in the tissue during the surgical procedure and in the hours immediately following the closure of the incision. The choice of antibiotic will depend on the typical flora of each healthcare centre, the resistance map and the surgical site. For long surgeries, when the duration exceeds twice the half-life of the antibiotic, the dose should be repeated ${ }^{14,15}$.

The use of antibiotic prophylaxis protocols facilitates adequacy, and in our hospital, we have a protocol that is periodically updated based on the recommendations in the literature. The protocol is reviewed and updated every two years by the infections commission.

The objective of our study was to evaluate the adequacy of the antibiotic prophylaxis to our protocol in patients undergoing neck surgery and the relationship between the adequacy of antibiotic prophylaxis and the incidence of SSI.

\footnotetext{
${ }^{1}$ Department of Preventive Medicine, Alcorcón Foundation University Hospital, C/ Budapest 1, 28922 Alcorcón, Madrid, Spain. ${ }^{2}$ Department of Medical Specialities and Public Health, Rey Juan Carlos University, Alcorcón, Madrid, Spain. ${ }^{3}$ Department of Otorhinolaryngology, Alcorcón Foundation University Hospital, Alcorcón, Madrid, Spain. ${ }^{\bowtie}$ email: grodriguez@fhalcorcon.es
} 


\begin{tabular}{|l|l|l|}
\hline & Antibiotic & Time \\
\hline Standard & Cefazolin $2 \mathrm{~g}$ iv or amoxicillin-clavulanic acid $2 \mathrm{~g}$ iv & Prior to anaesthetic induction \\
\hline In cases of allergy to beta-lactams & Clindamycin $600 \mathrm{mg}$ iv + gentamicin $3-5 \mathrm{mg} / \mathrm{kg} / 24 \mathrm{~h}$ & Prior to anaesthetic induction \\
\hline
\end{tabular}

Table 1. Antibiotic prophylaxis protocol in otorhinolaryngological surgery.

\begin{tabular}{|l|l|r|l|}
\hline ICD-9-CM code & Intervention & N & \% \\
\hline 30.1 & Hemilaryngectomy & 1 & 0.7 \\
\hline 30.21 & Epiglottectomy & 0 & 0 \\
\hline 30.22 & Vocal cordectomy & 56 & 40 \\
\hline 30.29 & Other partial laryngectomy & 10 & 7.1 \\
\hline 30.3 & Total laryngectomy & 21 & 15 \\
\hline 30.4 & Radical laryngectomy & 8 & 5.7 \\
\hline 31.45 & Open biopsy of larynx and trachea & 8 & 5.7 \\
\hline 40.40 & Radical neck dissection & 4 & 2.9 \\
\hline 40.41 & Radical neck dissection, unilateral & 29 & 20.7 \\
\hline 40.42 & Radical neck dissection, bilateral & 3 & 2.2 \\
\hline Total & & 140 & 100.0 \\
\hline
\end{tabular}

Table 2. Distribution of surgical interventions.

\section{Methods}

A prospective cohort study was conducted from January 2011 to December 2019. Consecutive patients over 18 years old who underwent neck surgery at the Alcorcón Foundation University Hospital (Hospital Universitario Fundación Alcorcón-HUFA) were sampled. Patients who at the time of surgery had an active infection or were receiving antibiotic treatment were excluded. The study was approved by the Ethics and Clinical Research Committee of HUFA (number 9/14).

The sample size was calculated for an estimated proportion of compliance with the antibiotic prophylaxis protocol of $85 \%$, a confidence level of $95 \%$, an accuracy of $10 \%$ and considering losses of $5 \%$. Thus, it was considered necessary to include 52 patients.

Sociodemographic variables (age, sex), patient comorbidities (cancer, diabetes, chronic obstructive pulmonary disease (COPD), obesity, liver cirrhosis, malnutrition, addiction to parenteral drugs, neutropenia, kidney failure, immunodeficiency), surgical risk according to the American Society of Anaesthesiologists (ASA) classification, surgery-related variables (type of surgery, duration, International Classification of Diseases (ICD-9-CM) diagnosis, drainage, shaving or transfusion), antibiotic prophylaxis-related items (election, time of administration, administration route, dose, duration), compliance with the protocol and SSI-related variables (diagnosis of infection, microorganism and location) were considered. Antibiotic prophylaxis stated in the hospital protocol is shown in Table 1 and it was prescribed for all otorhinolaryngological surgery undergoing laryngectomy or oral or pharyngeal mucosal incision, either in clean, clean-contaminated or contaminated surgery. Antibiotic prophylaxis was considered adequate when it conformed to all items of the protocol. In case of protocol inadequacy, the reason for inadequacy was recorded as follows: time of administration (the dose was not administered 30-60 min before surgery), election (the antibiotic administered differed from that specified in the protocol), duration (prophylaxis was prescribed more than $24 \mathrm{~h}$ ), administration route (administered by a route other than intravenous) or dose (the dose was different from that described in the protocol). Compliance was defined as the percentage of antibiotic prophylaxis administered when indicated. The diagnosis of SSI was made based on the Centres for Disease Control and Prevention (CDC) criteria ${ }^{16}$ and was evaluated jointly by the Preventive Medicine Unit and the Otorhinolaryngology Service. The surgical procedures included are shown in Table 2 and ICD-9-CM codes 30.22, 'Vocal cordectomy', and 31.45, 'Open biopsy of the larynx and trachea', were classified as clean surgeries.

Clinical follow-up of patients was performed from the time of surgery to 30 days after, which is the maximum incubation period for SSIs in surgeries not involving implant placement. They were actively monitored from the time of surgery until discharge and data were collected using an ad hoc form from the following data sources: hospital electronic medical records for surgery and hospital stay-related variables, in-hospital readmission, outpatients' revision and care provided in the hospital's emergency department. HORUS, the clinical history platform of the Community of Madrid for primary health-care was also used, which allowed follow-up through primary care visits from discharge to the end of the incubation period.

Statistical analysis. A descriptive analysis of the quantitative variables was performed using the mean and standard deviation or the median and interquartile range (IQR) if the variables were not normally distributed; these variables were compared using Student's t test or the Mann-Whitney test in cases of nonnormality. Quali- 


\begin{tabular}{|c|c|}
\hline Variable & $\mathbf{N}(\%)$ \\
\hline Mean age (years)/standard deviation & $65.7(12.5)$ \\
\hline \multicolumn{2}{|l|}{ Intrinsic and extrinsic factors } \\
\hline Cancer & $115(82.7)$ \\
\hline Diabetes & $41(29.5)$ \\
\hline Chronic obstructive pulmonary disease & $26(18.7)$ \\
\hline Obesity & $11(7.9)$ \\
\hline Liver cirrhosis & $6(4.3)$ \\
\hline Malnutrition & $6(4.3)$ \\
\hline Renal insufficiency & $4(2.9)$ \\
\hline Immunodeficiency & $1(0.7)$ \\
\hline Drainage & $54(38.8)$ \\
\hline Shaving & $7(5.0)$ \\
\hline Transfusion & $1(0.7)$ \\
\hline \multicolumn{2}{|l|}{ Surgery characteristics } \\
\hline \multicolumn{2}{|l|}{ American Society of Anesthesiologists index } \\
\hline ASA 1 & $5(3.6)$ \\
\hline ASA 2 & $74(53.2)$ \\
\hline ASA 3 & $56(40.3)$ \\
\hline ASA 4 & $4(2.9)$ \\
\hline Duration of surgery $(\mathrm{min}) /$ standard deviation & $144(118)$ \\
\hline \multicolumn{2}{|l|}{ Wound class } \\
\hline Clean & $64(45.7)$ \\
\hline Clean-contaminated & $76(54.3)$ \\
\hline
\end{tabular}

Table 3. Demographic, clinical and surgical characteristics of patients undergoing head and neck surgery $(\mathrm{N}=140)$.

tative variables were described using frequency distributions and percentages and were compared using the Pearson $\chi^{2}$ test or Fisher's exact test, as appropriate. The cumulative incidence of SSI was calculated, as was the relationship between SSI and antibiotic prophylaxis adequacy using the relative risk (RR). Statistical analysis was performed in SPSS 23.0, and a p-value $<0.05$ was considered statistically significant.

Informed consent. This study was done in accordance with the strengthening the reporting of observational studies in epidemiology (STROBE) statement. Informed consent was obtained from all subjects.

\section{Results}

During the study period, 140 patients were included in the sample and all of the patients completed the 30-day follow up. The mean age was $65.8 \pm 12.4$ years. A total of $81.4 \%$ of the patients were male. Table 2 shows the surgical interventions performed and their distribution frequency. The demographic and clinical characteristics of the patients are summarized in Table 3. The median length of hospital stay was 3 days (IQR 1-14 days), and discharges were almost completely due to cure (97.9\%).

No patient undergoing neck surgery had an addiction to parenteral drugs or neutropenia. Most of the admissions were scheduled (94.3\%). The mean duration of surgery was $144 \pm 118 \mathrm{~min}$. The surgical checklist was properly completed for $66.5 \%$ of patients.

One patient in whom antibiotic prophylaxis was not indicated received cefazolin. The administration of antibiotic prophylaxis was indicated for 76 patients and was administered for 63 (compliance $83 \%$ ). For 4 patients, prophylaxis was not administered, and for 9 patients, data on this variable were not recorded. The administered prophylaxis was adequate for $85.7 \%$ of patients (95\% CI 75.0-92.3) (Fig. 1). The most frequent cause of inadequate antibiotic prophylaxis was the choice of antibiotic (9.5\%, 95\% CI 4.4-19.3), followed by duration (4.8\%, $95 \%$ CI 1.6-13.1) (Table 4). The most commonly used prophylactic antibiotic was amoxicillin-clavulanate (76.2\%), followed by cefazolin (11.1\%), clindamycin (6.3\%), ciprofloxacin (3.2\%), gentamicin (1.6\%) and vancomycin (1.6\%).

Nine patients were diagnosed with SSI, with an overall cumulative incidence of $6.4 \%$ (95\% CI 3.4-11.8). One of the infections occurred in the group of patients who did not receive prophylaxis The incidence of SSI in the group of patients with adequate antibiotic prophylaxis was $9.2 \%$ (95\% CI 1.5-17.0), lower than that of $22.2 \%$ (95\% CI 0.0-49.4) in the group of patients with inadequate antibiotic prophylaxis. Two of the patients who did not received prophylaxis had a SSI, with an overall cumulative incidence of $2.5 \%$ (95\% CI 0.0-6.0).

In terms of location, six SSIs were superficial, and three were deep. The most frequently isolated microorganism was Enterobacter cloacae (Fig. 2).

SSI occurred with a mean of $14.0 \pm 16.1$ days since the operation date. SSI was diagnosed in-hospital in seven patients and in the first week after discharge in two patients. Patients without SSI had a median length of hospital 


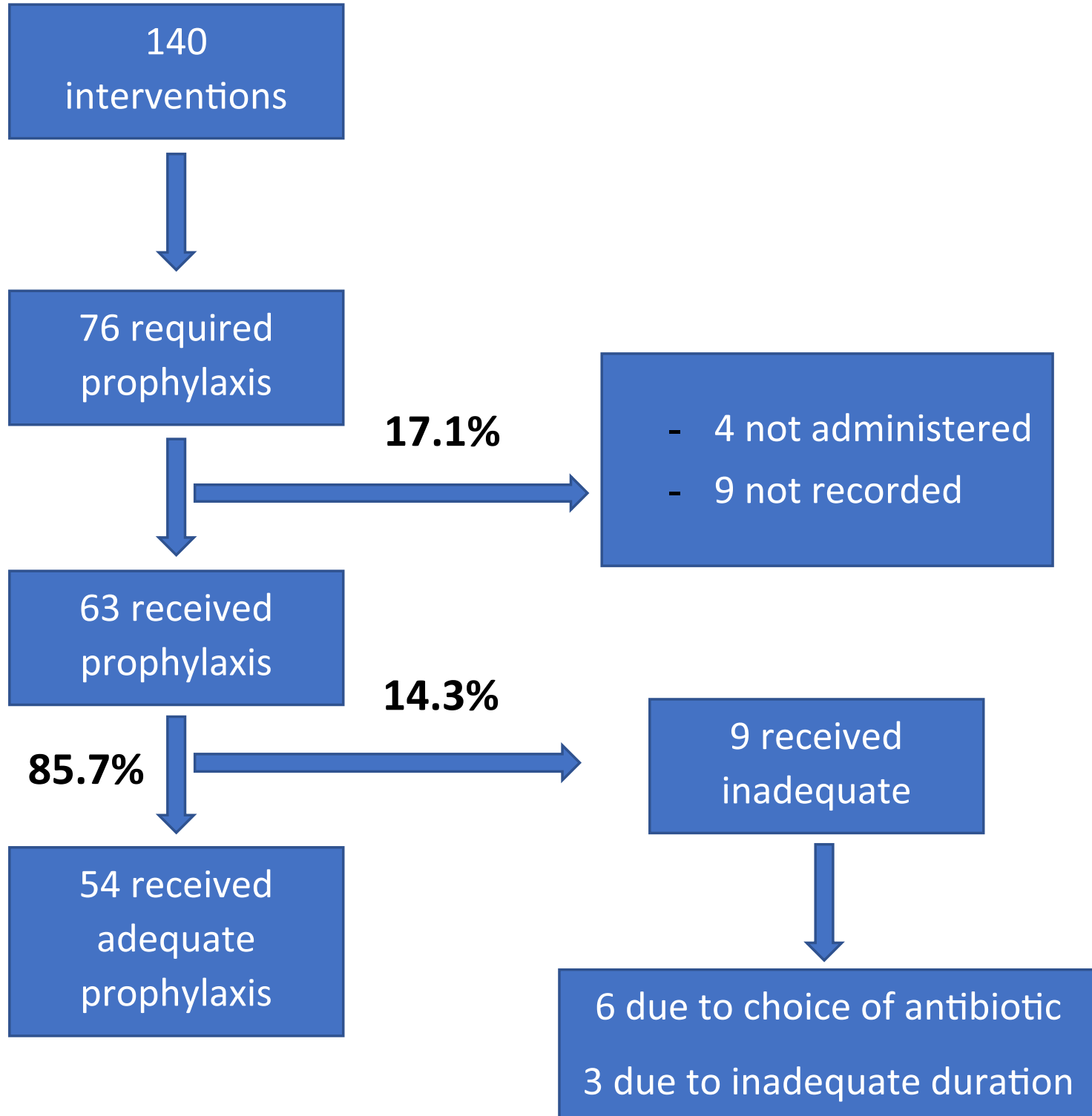

Figure 1. Study outline.

\begin{tabular}{|l|c|l|l|}
\hline Adequacy of antibiotic prophylaxis & $\mathbf{n}$ & $\mathbf{\%}$ & $\mathbf{9 5 \%} \mathbf{C I}$ \\
\hline Adequate & 54 & 85.7 & $75.0-92.3$ \\
\hline Inadequate (duration) & 3 & 4.8 & $1.6-13.1$ \\
\hline Inadequate (election) & 6 & 9.5 & $4.4-19.3$ \\
\hline Inadequate (route) & 0 & 0 & - \\
\hline Inadequate (dose) & 0 & 0 & - \\
\hline Inadequate (time of administration) & 0 & 0 & - \\
\hline Total & 63 & $100 \%$ & - \\
\hline
\end{tabular}

Table 4. Compliance and adequacy of antibiotic prophylaxis use to the hospital protocol ( $\mathrm{n}=76$, compliance $83 \%)$.

stay of 3 days (IQR 1-13 days), while for patients with SSI, the median stay was 26 days (IQR 15.5-41 days) $(\mathrm{p}<0.05)$.

There was no significant relationship neither between inadequate antibiotic prophylaxis and the incidence of SSI $(\mathrm{RR}=2.4,95 \% \mathrm{CI} 0.6-10.6)$ nor between patients with or without indication of prophylaxis and the incidence of SSI $(\mathrm{RR}=0.23,95 \% \mathrm{CI} 0.05-1.1)$. 


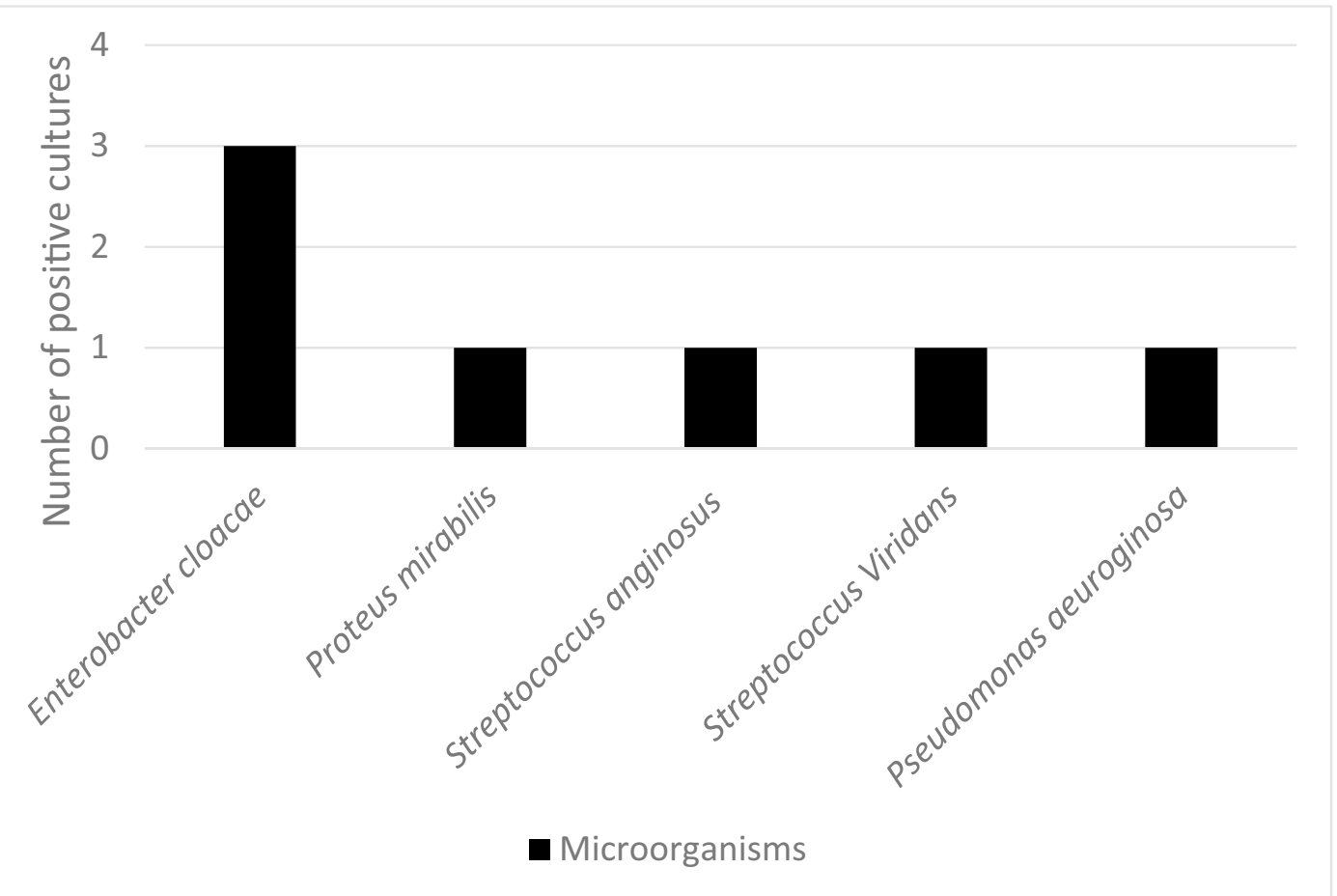

Figure 2. Surgical Site Infection aetiology.

\section{Discussion}

A low incidence of SSI is directly related to an adequate surgical technique and is commonly used as an indicator of quality and safety in hospital care ${ }^{17}$. The incidence of SSI in this study was $6.4 \%$, higher than the incidence reported by the CDC $(3.5 \%)^{18}$ and lower than that reported in other studies ${ }^{8,9,19-21}$, which have described an incidence of up to $85 \%$. Our patients were mostly men ( $84 \%$ men and $16 \%$ women) with a mean age of 65.8 years, in line with what has been reported in other neck surgery studies ${ }^{22}$.

Up to $60 \%$ of SSIs can be prevented with evidence-based clinical practices such as preoperative preparation or optimal antibiotic selection ${ }^{12,23,24}$. In neck surgery, there are few studies that evaluate the effect of antibiotic prophylaxis on the incidence of SSI. The results of our study showed a non-significant reduction in SSIs as a function of the administration of adequate antibiotic prophylaxis. There is some controversy between studies that show this relationship ${ }^{25,26}$ and others that do not show the efficacy of antibiotic prophylaxis ${ }^{27}$, although a recent systematic review by Vander Porten et al. ${ }^{28}$ concludes that the administration of antibiotic prophylaxis clearly reduces the incidence of SSIs in clean-contaminated surgery.

The administration of the prophylactic antibiotic between 30 and $60 \mathrm{~min}$ before the surgical incision reduces SSIs and should be repeated if the surgery lasts more than $4 \mathrm{~h}^{29}$. In our study, antibiotic prophylaxis was indicated for 67 patients (47.9\%), and its administration was adequate for $85.7 \%$ (95\% CI 75.0-92.3) of them. The surgeries for which antibiotic prophylaxis was not indicated were those classified under ICD-9-CM codes 30.22, "Vocal cordectomy", and 31.45, "Open biopsy of the larynx and trachea", which are classified as clean surgeries and for which the efficacy of antibiotic prophylaxis has not been observed ${ }^{30,31}$. Two patients in our series who developed SSI received inadequate prophylaxis, and the percentage of patients who did not receive prophylaxis, even when indicated, was $6.0 \%$, which was lower than in other studies ${ }^{32,33}$ and higher than that reported by Hemssen et al. ${ }^{34}$. Our percentage of adequacy $(85.7 \%)$ was high; however, it was lower than that reported in other studies ${ }^{35}$, higher than that of a study conducted in our $\operatorname{area}^{36}$ and in line with that of Takahashi et al..$^{37}$. The main cause of inadequacy of the antibiotic prophylaxis protocol in our study was the choice of antibiotic, which is the most frequently reported cause of inadequacy ${ }^{38}$.

The microorganisms isolated from SSIs during neck surgery are very diverse; the most frequent are Staphylococcus aureus, Klebsiella pneumoniae, Pseudomonas aeruginosa, enterobacteria and Enterococcus spp. ${ }^{23,39,40}$, which are common colonizing microorganisms of the airways. In our study, most of the microorganisms were gram negative (Enterobacter cloacae), which is consistent with other studies that describe this group of microorganisms as the most frequently identified in postoperative infections in neck surgery ${ }^{41}$.

Monitoring the adequacy of the items of the antibiotic prophylaxis protocols can help controlling SSIs and the antibiotics to be effective, as shows different previous research ${ }^{35,38,42}$.

The possible limitations of the study include the small sample size, although a sample size estimation was performed to ensure that the percentage of antibiotic prophylaxis adequacy was adequately estimated. The incidence of infection may be underestimated by the loss of exceptional cases of superficial infections with minimal symptoms for which the patient did not contact the emergency department, the otorhinolaryngology service or the primary care doctor. We believe that this bias has been controlled because the patients were followed during 
admission and after discharge and their attendance at different care facilities was prospectively evaluated for 30 days, the maximum incubation period of an SSI in surgeries without implant placement.

We can conclude that antibiotic prophylaxis is one of the most cost-effective measures for reducing the incidence of SSIs, and compliance with existing protocols is a measure that is used to assess the quality of health care. Adequacy of antibiotic prophylaxis in our study was high, and the main cause of inadequacy was the choice of antibiotic. We observed a reduction in the incidence of SSI during neck surgery in patients who were adequately administered prophylaxis, although this relationship was not statistically significant. So, we would recommend to monitor the adequacy of the items of the antibiotic prophylaxis protocols, in order to control SSIs.

\section{Data availability}

The datasets generated and analyzed during the current study are not publicly available. Because they are archived in the clinical databases of the Alcorcón Foundation University Hospital they are only used for scientific purposes. Datasets are available from the corresponding author upon justified request.

Received: 28 January 2021; Accepted: 28 July 2021

Published online: 12 August 2021

\section{References}

1. Magill, S. S. et al. Changes in prevalence of health care-associated infections in U.S. Hospitals. N. Engl. J. Med. 379, 1732-1744 (2018).

2. Grupo de Trabajo EPINE. ESTUDIO EPINE-EPPS 2019 Informe global de España. https://epine.es/api/documento-publico/2019\% 20EPINE\%20Informe\%20Espa\%C3\%B1a\%2027112019.pdf/reports-esp (Accessed 25 December 2020).

3. Harrop, J. S. et al. Contributing factors to surgical site infections. J. Am. Acad. Orthop. Surg. 20, 94-101 (2012).

4. Young, P. Y. \& Khadaroo, R. G. Surgical site infections. Surg. Clin. N. Am. 94, 1245-1264 (2014).

5. European Centre for Disease Prevention and Control. Healthcare-associated infections: Surgical site infections. In Annual Epidemiological Report for 2017. https://www.ecdc.europa.eu/en/publications-data/healthcare-associated-infections-surgical-site-infec tions-annual-1 (Accessed 01 April 2021)].

6. Johnson, J. T. \& Wagner, R. L. Infection following uncontaminated head and neck surgery. Arch. Otolaryngol. Head Neck Surg. 113, 368-369 (1987).

7. Koshkareva, Y. A. \& Johnson, J. T. What is the perioperative antibiotic prophylaxis in adult oncologic head and neck surgery? Laryngoscope 124, 1055-1056 (2014).

8. Busch, C. J. et al. Postoperative antibiotic prophylaxis in clean-contaminated head and neck oncologic surgery: A retrospective cohort study. Eur. Arch. Otorhynolaryngol. 273, 2805-2811 (2016).

9. Simo, R. \& French, G. The use of prophylactic antibiotics in head and neck oncological surgery. Curr. Opin. Otolaryngol. Head Neck Surg. 14, 55-61 (2006).

10. Coello, R. et al. Adverse impact of surgical site infections in English hospitals. J. Hosp. Infect. 60, 93-103 (2005).

11. Alfonso, J. L. et al. Are we really seeing the total costs of surgical site infections? A Spanish study. Wound Repair Regen. 15, 474-481 (2007).

12. Protocolo Infección Quirúrgica Zero. Sociedad Española de Medicina Preventiva Salud Pública e Higiene (2017).

13. Spruce, L. Back to basics: Preventing surgical site infections. AORN J. 99, 600-608 (2014).

14. Horan, T., Andrus, M. \& Dudeck, M. CDC/NHSN surveillance definition of health care-associated infection and criteria for specific types of infections in the acute care setting. Am. J. Infect. Control. 36, 309-322 (2008).

15. Bratzler, D. \& Houck, P. Antimicrobial prophylaxis for surgery: An advisory statement from the National Surgical Infection Prevention Project. Am. J. Surg. 189, 395-404 (2005).

16. CDC/NHSN. Procedure-associated Module. Surgical Site Infection (SSI) Event (2016). http://www.cdc.gov/nhsn/PDFs/pscManual/ 9pscSSIcurrent.pdf (Accessed 01 April 2021).

17. Chinn, R. et al. Standardized infection ratio for surgical site infection after colon surgery: Discord in models measuring healthcare quality. Infect. Control Hosp. Epidemiol. 37, 1378-1382 (2016).

18. Edwards, J. R. et al. National Healthcare Safety Network (NHSN) report: Data summary for 2006 through 2008, issued December 2009. Am. J. Infect. Control. 37, 783-805 (2009).

19. Henry, J. S., Buffet-Bataillon, S., Deberge, S. \& Jegoux, F. Predictive factors for surgical site infection in head and neck cancer surgery: A case-control study. Rev. Laryngol. Otol. Rhinol. (Bord.) 135, 121-126 (2014).

20. Goyal, N. et al. Surgical site infections in major head and neck surgeries involving pedicled flap reconstruction. Ann. Otol. Rhinol. Laryngol. 126, 20-28 (2017).

21. Son, H. J., Roh, J. L., Choi, S. H., Nam, S. Y. \& Kim, S. Y. Nutritional and hematologic markers as predictors of risk of surgical site infection in patients with head and neck cancer undergoing major oncologic surgery. Head Neck 40, 596-604 (2018).

22. Rodríguez-Valiente, A., Segovia-Gómez, T., Roldán-Fidalgo, A., Bermejo-Martínez, M. \& García-Berrocal, J. Elaboración de un protocolo para el manejo del sitio quirúrgico en cirugía de cabeza y cuello: Una cura eficaz, efectiva y eficiente en pacientes laringectomizados. Gerokomos. 25, 81-89 (2014).

23. Meeks, D. W. et al. Compliance with guidelines to prevent surgical site infections: As simple as 1-2-3? Am. J. Surg. 201, 76-83 (2011).

24. Alonso-García, M. et al. Impacto de la adecuación del protocolo de preparación prequirúrgica en la incidencia de infección de localización quirúrgica en cirugía cervical. J. Healthcare Qual. Res. 34, 53-58 (2019).

25. Velanovich, V. A meta-analysis of prophylactic antibiotics in head and neck surgery. Plast. Reconstr. Surg. 87, 429-434 (1991).

26. Bartella, A. et al. Prospective comparison of perioperative antibiotic management protocols in oncological head and neck surgery. J. Craniomaxillofac. Surg. 45, 1078-1082 (2017).

27. Dionigi, G., Rovera, F., Boni, L., Castano, P. \& Dionigi, R. Surgical site infections after thyroidectomy. Surg. Infect. 7, S117-S120 (2006).

28. Vander Poorten, V. et al. Perioperative antibiotics in clean-contaminated head and neck surgery: A systematic review and metaanalysis. Adv. Ther. 37, 1360-1380 (2020).

29. Dulguerov, P., Leuchter, I., Harbarth, S. \& Pittet, D. Antibiotic prophylaxis in head and neck surgery. Med. Hyg. 61, 1974-1982 (2003).

30. Chiesa-Estomba, C. M. et al. Antibiotic prophylaxis in clean head and neck surgery: An observational retrospective single-centre study. Ear Nose Throat J. 98, 362-365 (2019).

31. Chiesa-Estomba, C. M. et al. Systematic review of international guidelines for perioperative antibiotic prophylaxis in Head \& Neck Surgery. A YO-IFOS Head \& Neck Study Group Position Paper. Head Neck. 41, 3434-3456 (2019). 
32. Azzam, R., Hamadé, N., Bedrossian, N. \& Assaad, C. Survey of antimicrobial prophylaxis for surgical procedures in Lebanese hospitals. J. Med. Liban. 50, 211-215 (2002).

33. Lallemand, S., Thouverez, M., Bailly, P., Bertrand, X. \& Talon, D. Non-observance of guidelines for surgical antimicrobial prophylaxis and surgical site infections. Pharm. World Sci. 24, 95-99 (2002).

34. Hermsen, E., Shull, S., Puumala, S. \& Rupp, M. Improvement in prescribing habits economic outcomes associated with the introduction of a standardized approach for surgical antimicrobial prophylaxis. Infect. Control Hosp. Epidemiol. 29, 457-461 (2008).

35. Del Moral Luque, J. A. et al. Incidence of surgical site infection in colon surgery and antibiotic prophylaxis adequacy: Prospective cohort study. Ann. Sist. Sanit. Navar. 40, 371-377 (2017).

36. Díaz-Agero-Pérez, C., Pita-López, M. J., Robustillo-Rodela, A., Figuerola-Tejerina, A. \& Monge-Jodrá, V. Evaluación de la infección de sitio quirúrgico en 14 hospitales de la Comunidad de Madrid: estudio de incidencia. Enferm. Infecc. Microbiol. Clin. 29, 257-262 (2011).

37. Takahashi, Y. et al. Implementation of a hospital-wide project for appropriate antimicrobial prophylaxis. J. Infect. Chemother. 16, 418-423 (2010).

38. Del-Moral-Luque, J. A. et al. Evaluación de la adecuación de la profilaxis antibiótica en la cirugía de recto. Rev. Esp. Quimioter. 30, 14-18 (2017).

39. Hirakawa, H. et al. Surgical site Infection in clean-contaminated head and neck cancer surgery: Risk factors and prognosis. Eur. Arch. Otorhinolaryngol. 270, 1115-1123 (2012).

40. Veve, M. P., Davis, S. L., Williams, A. M., McKinnon, J. E. \& Ghanem, T. A. Considerations for antibiotic prophylaxis in head and neck cancer surgery. Oral Oncol. 74, 181-187 (2017).

41. Skitarelic, N., Morovic, M. \& Malestar, D. Antibiotic prophylaxis in clean-contaminated head and neck oncological surgery. J. Craniomaxillofac. Surg. 35, 15-20 (2007).

42. Gil-Conesa, M. et al. Evaluation of compliance with the antibiotic prophylaxis protocol in hysterectomy. Prospective cohort study. Rev. Esp. Quimioter. 33, 180-186 (2020).

\section{Acknowledgements}

The authors thank the European Regional Development Fund (ERDF) and the Health Research Fund (Fondo de Investigación Sanitaria/FIS) supporting the research project PI19/00987, and the HUFA 2018 Grant, which enabled the completion of this study. The authors also thank Mr Sergio Rodríguez Villar for his help and support in registering data and in the design and management of the data bases of the study.

\section{Author contributions}

M.A.G. and G.R.C. designed the study, analyzed the data and wrote the manuscript. A.T.M., J.M.A.F. and F.M.D.L.R.A. were responsible for the collection of clinical data, interpreted the results and revised the manuscript critically. D.R.V., A.G.D.M. and M.D.P. analyzed and interpreted the data and revised the manuscript critically. All authors read and approved the final manuscript.

\section{Funding}

This study was funded the European Regional Development Fund (ERDF) and the Health Research Fund (Fondo de Investigación Sanitaria/FIS) supporting the research project PI19/00987.

\section{Competing interests}

The authors declare no competing interests.

\section{Additional information}

Correspondence and requests for materials should be addressed to G.R.-C.

Reprints and permissions information is available at www.nature.com/reprints.

Publisher's note Springer Nature remains neutral with regard to jurisdictional claims in published maps and institutional affiliations.

(c) Open Access This article is licensed under a Creative Commons Attribution 4.0 International License, which permits use, sharing, adaptation, distribution and reproduction in any medium or format, as long as you give appropriate credit to the original author(s) and the source, provide a link to the Creative Commons licence, and indicate if changes were made. The images or other third party material in this article are included in the article's Creative Commons licence, unless indicated otherwise in a credit line to the material. If material is not included in the article's Creative Commons licence and your intended use is not permitted by statutory regulation or exceeds the permitted use, you will need to obtain permission directly from the copyright holder. To view a copy of this licence, visit http://creativecommons.org/licenses/by/4.0/.

(c) The Author(s) 2021 